\title{
A Qualitative Analysis of Patients' Experience With Hospitalist Service Handovers
}

\author{
Charlie M. Wray, DO ${ }^{1 \star}$, Jeanne M. Farnan, MD, MHPEE ${ }^{1,2}$, Vineet M. Arora, MD, MAPP², David O. Meltzer, MD, PhD ${ }^{1,4,5}$
}

\begin{abstract}
${ }^{1}$ Section of Hospital Medicine, University of Chicago Medical Center, Chicago, Illinois; ${ }^{2}$ Pritzker School of Medicine, University of Chicago, Chicago, Illinois; ${ }^{3}$ Section of General Internal Medicine, University of Chicago Medical Center, Chicago, Illinois; ${ }^{4}$ Department of Economics, University of Chicago, Chicago, Illinois; ${ }^{5}$ Harris School of Public Policy Studies, University of Chicago, Chicago, Illinois.
\end{abstract}

BACKGROUND: Inpatient service handoffs occur when physicians who care for hospitalized patients end a period of clinical service and handover a panel of patients to an oncoming physician. Despite the large amount of research on handoffs, none has described the patient perspective when cared for by a hospitalist physician during a service handoff.

OBJECTIVE: To describe hospitalized patients' experiences regarding inpatient service changes, and develop a conceptual framework to inform future efforts to improve servicelevel handoffs.

METHODS: Interview-based qualitative analysis using indepth, semistructured interviews of hospitalized patients on a nonteaching hospitalist service. Patients were interviewed between October 2014 and December 2014 at an academic medical center whose inpatient stay spanned a weekly service change. We utilized an inductive approach with no a priori hypotheses and used a constant comparative method to generate emerging themes to develop a conceptual model that captured the patient experience during the transition.

RESULTS: Of patients who agreed to participate (40/43), most $(85 \%)$ were unaware that a transition had occurred between their hospitalists. Six major themes emerged related to patients' experiences with hospitalist service handoffs: (1) importance of physician-patient communication, (2) desire for transparency in transitions, (3) an indifference toward transitions, (4) importance of hospitalist-specialist communication, (5) formation of new opportunities from a transition, and (6) effects of bedside manner.

CONCLUSIONS: Hospitalized patients desire improved communication and a more formalized transition process between hospitalists during service handoffs. Hospitalists should recognize that this transition may represent an opportunity to improve the hospitalized patient's experience and satisfaction. Journal of Hospital Medicine 2016;11:675-681. (C) 2016 Society of Hospital Medicine
Studies examining the importance of continuity of care have shown that patients who maintain a continuous relationship with a single physician have improved outcomes. ${ }^{1,2}$ However, most of these studies were performed in the outpatient, rather than the inpatient setting. With over 35 million patients admitted to hospitals in 2013, along with the significant increase in hospital discontinuity over recent years, the impact of inpatient continuity of care on quality outcomes and patient satisfaction is becoming increasingly relevant. ${ }^{3,4}$

Service handoffs, when a physician hands over treatment responsibility for a panel of patients and is not expected to return, are a type of handoff that contributes to inpatient discontinuity. In particular, service handoffs between hospitalists are an especially common

*Address for correspondence and reprint requests: Charlie M. Wray, DO, Hospitalist Research Scholar-Clinical Associate, Section of Hospital Medicine, University of Chicago Medical Center, 5841 S. Maryland Avenue, MC 5000, Chicago, IL 60637; Telephone: 415-595-9662; E-mail: cwray@medicine.bsd.uchicago.edu

Additional Supporting Information may be found in the online version of this article.

Received: December 15, 2015; Revised: April 4, 2016; Accepted: April 18,2016

2016 Society of Hospital Medicine DOI 10.1002/jhm.2608

Published online in Wiley Online Library (Wileyonlinelibrary.com). and inherently risky type of transition, as there is a severing of an established relationship during a patient's hospitalization. Unfortunately, due to the lack of evidence on the effects of service handoffs, current guidelines are limited in their recommendations. ${ }^{5}$ Whereas several recent studies have begun to explore the effects of these handoffs, no prior study has examined this issue from a patient's perspective. ${ }^{6-8}$

Patients are uniquely positioned to inform us about their experiences in care transitions. Furthermore, with patient satisfaction now affecting Medicare reimbursement rates, patient experiences while in the hospital are becoming even more significant. ${ }^{9}$ Despite this emphasis toward more patient-centered care, no study has explored the hospitalized patient's experience with hospitalist service handoffs. Our goal was to qualitatively assess the hospitalized patients' experiences with transitions between hospitalists to develop a conceptual model to inform future work on improving inpatient transitions of care.

\section{METHODS}

\section{Sampling and Recruitment}

We conducted bedside interviews of hospitalized patients at an urban academic medical center from October 2014 through December 2014. The hospitalist service consists of a physician and an advanced nurse practitioner (ANP) 
who divide a panel of patients that consist of general medicine and subspecialty patients who are often comanaged with hepatology, oncology, and nephrology subspecialists. We performed a purposive selection of patients who could potentially comment on their experience with a hospitalist service transition using the following method: 48 hours after a service handoff (ie, an outgoing physician completing 1 week on service, then transfers the care of the patient to a new oncoming hospitalist), oncoming hospitalists were approached and asked if any patient on their service had experienced a service handoff and still remained in the hospital. A 48-hour time period was chosen to give the patients time to familiarize themselves with their new hospitalist, allowing them to properly comment on the handoff. Patients who were managed by the ANP, who were non-English speaking, or who were deemed to have an altered mental status based on clinical suspicion by the interviewing physician (C.M.W.) were excluded from participation. Following each weekly service transition, a list of patients who met the above criteria was collected from 4 nonteaching hospitalist services, and were approached by the primary investigator (C.M.W.) and asked if they would be willing to participate. All patients were general medicine patients and no exclusions were made based on physical location within the hospital. Those who agreed provided signed written consent prior to participation to allow access to the electronic health records (EHRs) by study personnel.

\section{Data Collection}

Patients were administered a 9-question, semistructured interview that was informed by expert opinion and existing literature, which was developed to elicit their perspective regarding their transition between hospitalists. ${ }^{10,11}$ No formal changes were made to the interview guide during the study period, and all patients were asked the same questions. Outcomes from interim analysis guided further questioning in subsequent interviews so as to increase the depth of patient responses (ie, "Can you explain your response in greater depth?"). Prior to the interview, patients were read a description of a hospitalist, and were reminded which hospitalists had cared for them during their stay (see Supporting Information, Appendix 1 , in the online version of this article). If family members or a caregiver were present at the time of interview, they were asked not to comment. No repeat interviews were carried out.

All interviews were performed privately in singleoccupancy rooms, digitally recorded using an iPad (Apple, Cupertino, CA) and professionally transcribed verbatim (Rev, San Francisco, CA). All analysis was performed using MAXQDA Software (VERBI Software $\mathrm{GmbH}$, Berlin, Germany). We obtained demographic information about each patient through chart review

\section{TABLE 1. Respondent Characteristics}

\begin{tabular}{lc}
\hline & Value \\
\hline Response rate, $n(\%)$ & $40 / 43(93)$ \\
Age, mean \pm SD & $54.5 \pm 15$ \\
Sex, $n(\%)$ & \\
Female & $26(65)$ \\
Male & $14(35)$ \\
Race, $n$ (\%) & \\
African American & $23(58)$ \\
White & $16(40)$ \\
Hispanic & $1(2)$ \\
Median LOS at time of interview, d (IQR) & $6.5(4-8)$ \\
Median no. of hospitalists at time of interview, $n$ (IQR) & $2.0(1-3)$ \\
\hline
\end{tabular}

NOTE: Abbreviations: IQR, interquartile range; LOS, length of stay; SD, standard deviation.

\section{Data Analysis}

Grounded theory was utilized, with an inductive approach with no a priori hypothesis. ${ }^{12}$ The constant comparative method was used to generate emerging and reoccurring themes. ${ }^{13}$ Units of analysis were sentences and phrases. Our research team consisted of 4 academic hospitalists, 2 with backgrounds in clinical medicine, medical education, and qualitative analysis (J.M.F., V.M.A.), 1 as a clinician (C.M.W.), and 1 in health economics (D.O.M.). Interim analysis was performed on a weekly basis (C.M.W.), during which time a coding template was created and refined through an iterative process (C.M.W., J.M.F.). All disagreements in coded themes were resolved through group discussion until full consensus was reached. Each week, responses were assessed for thematic saturation. ${ }^{14}$ Interviews were continued if new themes arose during this analysis. Data collection was ended once we ceased to extract new topics from participants. A summary of all themes was then presented to a group of 10 patients who met the same inclusion criteria for respondent validation and member checking. All reporting was performed within the Standards for Reporting Qualitative Research, with additional guidance derived from the Consolidated Criteria for Reporting Qualitative Research. ${ }^{15,16}$ The University of Chicago Institutional Review Board approved this protocol.

\section{RESULTS}

In total, 43 eligible patients were recruited, and 40 $(93 \%)$ agreed to participate. Interviewed patients were between 51 and $65(39 \%)$ years old, had a mean age of $54.5( \pm 15)$ years, were predominantly female (65\%), African American (58\%), had a median length of stay at the time of interview of 6.5 days (interquartile range [IQR]: 4-8), and had an average of 2.0 (IQR: $1-3)$ hospitalists oversee their care at the time of interview (Table 1). Interview times ranged from 10:25 to 25:48 minutes, with an average of $15: 32$ minutes. 
We identified 6 major themes on patient perceptions of hospitalist service handoffs including (1) physicianpatient communication, (2) transparency in the hospitalist transition process, (3) indifference toward the hospitalist transition, (4) hospitalist-subspecialist communication, (5) recognition of new opportunities due to a transition, and (6) hospitalists' bedside manner (Table 2).

\section{Physician-Patient Communication}

Communication between the physician and the patient was an important element in patients' assessment of their experience. Patient's tended to divide physicianpatient communication into 2 categories: good communication, which consisted of "open communication" (patient 1) and patient engagement, and bad communication, which was described as physicians not sharing information or taking the time to explain the course of care in "words that I'll understand" (patient 2). Patients also described dissatisfaction with redundant communication between multiple hospitalists and the frustration of often having to describe their clinical course to multiple providers.

\section{Transparency in Communication}

The desire to have greater transparency in the handoff process was another common theme. This was likely due to the fact that $34 / 40(85 \%)$ of surveyed patients were unaware that a service changeover had ever taken place. This lack of transparency was viewed to have further downstream consequences as patients stated that there "should be a level of transparency, and when it's not, then there is always trust issues" (patient 1). Upon further questioning as to how to make the process more transparent, many patients recommended a formalized, face-to-face introduction involving the patient and both hospitalists, in which the outgoing hospitalist would, "bring you [oncoming hospitalist] in, and introduce you to me" (patient 4).

Patients often stated that given the large spectrum of physicians they might encounter during their stay (ie, medical student, resident, hospitalist attending, subspecialty fellow, subspecialist attending), clearer definitions of physicians' roles are needed.

\section{Hospitalist-Specialist Communication}

Concern about the communication between their hospitalist and subspecialist was another predominant theme. Conflicting and unclear directions from multiple services were especially frustrating, as a patient stated, "One guy took me off this pill, the other guy wants me on that pill, I'm like okay, I can't do both" (patient 8). Furthermore, a subset of patients referenced their subspecialist as their primary care provider and preferred their subspecialist for guidance in their hospital course, rather than their hospitalist. This often appeared in cases where the patient had an established relationship with the subspecialist prior to their hospitalization.

\section{New Opportunities Due to Transition}

Patients expressed positive feelings toward service handoffs by viewing the transition as an opportunity for medical reevaluation by a new physician. Patients told of instances in which a specific complaint was not being addressed by the first physician, but would be addressed by the second (oncoming) physician. A commonly expressed idea was that the oncoming physician "might know something that he [Dr. B] didn't know, and since Dr. B was only here for a week, why not give him [oncoming hospitalist] a chance" (patient 10). Patients would also describe the transition as an opportunity to form, and possibly improve, therapeutic alliances with a new hospitalist.

\section{Bedside Manner}

Bedside manner was another commonly mentioned thematic element. Patients were often quick to forget prior problems or issues that they may have suffered because of the transition if the oncoming physician was perceived to have a good bedside manner, often described as someone who formally introduced themselves, was considered relaxed, and would take the time to sit and talk with the patient. As a patient put it, "[S]he sat down and got to know me... and asked me what I wanted to do" (patient 12). Conversely, patients described instances in which a perceived bad bedside manner led to a poor relationship between the physician and the patient, in which "trust and comfort" (patient 11) were sacrificed.

\section{Indifference Toward Transition}

In contrast to some of the previous findings, which called for improved interactions between physicians and patients, we also discovered a theme of indifference toward the transition. Several patients stated feelings of trust with the medical system, and were content with the service changeover as long as they felt that their medical needs were being met. Patients also tended to express a level of acceptance with the transition, and tended to believe that this "was the price we pay for being here [in the hospital]" (patient 7).

\section{Conceptual Model}

Following the collection and analysis of all patient responses, all themes were utilized to construct the ideal patient-centered service handoff. The ideal transition describes open lines of communication between all involved parties, is facilitated by multiple modalities, such as the EHRs and nursing staff, and recognizes the patient as the primary stakeholder (Figure 1).

\section{DISCUSSION}

To our knowledge, this is the first qualitative investigation of the hospitalized patient's experience with service handoffs between hospitalists. The patient perspective adds a personal and first-hand description of how fragmented care may impact the hospitalized patient experience. 


\begin{tabular}{|c|c|c|}
\hline Themes & Subthemes & Representative Quotes \\
\hline \multirow{5}{*}{ Physician-patient communication } & Patients dislike redundant communication with & "I mean it's just you always have to explain your situation over and over and over again." (patient 14) \\
\hline & oncoming hospitalist. & $\begin{array}{l}\text { "When I said it once already, then you're repeating it to another doctor... . I feel as if that hospitalist didn't talk } \\
\text { to the other hospitalist." (patient 7) }\end{array}$ \\
\hline & $\begin{array}{l}\text { Poor communication can negatively affect the } \\
\text { doctor-patient relationship. }\end{array}$ & $\begin{array}{l}\text { "They don't really want to explain things. They don't think I'll understand. I think ... yeah, I'm okay. You don't } \\
\text { even have to put it in layman's terms. I know medical. I'm in nursing school. I have a year left. But even if } \\
\text { you didn't know that, I would still hope you would try to tell me what was going on instead of just doing it } \\
\text { in your head, and treating it." (patient 2) }\end{array}$ \\
\hline & & $\begin{array}{l}\text { "I mean it's just you always have to explain your situation over and over and over again. After a while you just } \\
\text { stop trusting them." (patient 20) }\end{array}$ \\
\hline & $\begin{array}{l}\text { Good communication can positively affect the } \\
\text { doctor-patient relationship. }\end{array}$ & $\begin{array}{l}\text { "Just continue with the communication, the open communication, and always stress to me that I have a voice } \\
\text { and just going out of their way to do whatever they can to help me through whatever l'm going through." } \\
\text { (patient 1) }\end{array}$ \\
\hline \multirow[t]{6}{*}{ Transparency in transition } & $\begin{array}{l}\text { Patients want to be informed prior to a service } \\
\text { changeover. }\end{array}$ & $\begin{array}{l}\text { "I think they should be told immediately, even maybe given prior notice, like this may happen, just so you're } \\
\text { not surprised when it happens." (patient 15) }\end{array}$ \\
\hline & & $\begin{array}{l}\text { "When the doctor approached me, he let me know that he wasn't going to be here the next day and there was } \\
\text { going to be another doctor coming in. That made me feel comfortable." (patient 9) }\end{array}$ \\
\hline & $\begin{array}{l}\text { Patients desire a more formalized process in the } \\
\text { service changeover. }\end{array}$ & $\begin{array}{l}\text { "People want things to be consistent. People don't like change. They like routine. So, if he's leaving, you're } \\
\text { coming on, l'd like for him to bring you in, introduce you to me, and for you just assure me that l'll take } \\
\text { care of you." (patient 4) }\end{array}$ \\
\hline & & $\begin{array}{l}\text { "Just like when you get a new medication, you're given all this information on it. So when you get a new hos- } \\
\text { pitalist, shouldn't I get all the information on them? Like where they went to school, what they look like." } \\
\text { (patient 23) }\end{array}$ \\
\hline & $\begin{array}{l}\text { Patients want clearer definition of the roles the } \\
\text { physicians will play in their care. }\end{array}$ & $\begin{array}{l}\text { "The first time I was hospitalized for the first time I had all these different doctors coming in, and I had the res- } \\
\text { idency, and the specialists, and the department, and I don't know who's who. What I asked them to do is } \\
\text { when they come in the room, which they did, but introduce it a little more for me. Write it down like these } \\
\text { are the special team and these are the doctors because even though they come in and give me their } \\
\text { name, I have no idea what they're doing." (patient 5) }\end{array}$ \\
\hline & & $\begin{array}{l}\text { "Someone should explain the setup and who people are. Someone would say, 'Okay when you're in a hospital } \\
\text { this is your [doctor's] role.' Like they should have booklets and everything." (patient 19) }\end{array}$ \\
\hline \multirow[t]{3}{*}{ Indifference toward transition } & Many patients have trust in service changeovers. & $\begin{array}{l}\text { "[S]0 as long as everybody's on board and communicates well and efficiently, I don't have a problem with it." } \\
\text { (patient 6) }\end{array}$ \\
\hline & & "To me, it really wasn't no preference, as long as I was getting the care that I needed." (patient 21) \\
\hline & & "It's not a concern as long as they're on the same page." (patient 17) \\
\hline \multirow[t]{5}{*}{$\begin{array}{l}\text { Hospitalist-specialist } \\
\text { communication }\end{array}$} & $\begin{array}{l}\text { Patients are concerned about communication } \\
\text { between their hospitalist and their } \\
\text { subspecialists. }\end{array}$ & $\begin{array}{l}\text { "The more cooks you get in the kitchen, the more things get to get lost, so l'm always concerned that they're } \\
\text { not sharing the same information, especially when you're getting asked the same questions that you might } \\
\text { have just answered the last hour ago." (patient 9) }\end{array}$ \\
\hline & & "I don't know if the hospitalist are talking to them [subspecialist]. They haven't got time." (patient 35) \\
\hline & $\begin{array}{l}\text { Patients place trust in the communication } \\
\text { between hospitalist and subspecialist. }\end{array}$ & $\begin{array}{l}\text { "I think among the teams themselves. . which is my pain doctor, Dr. K's group, the oncology group itself, they } \\
\text { switch off and trade with each other and they all speak the same language so that works out good." } \\
\text { (patient 3) }\end{array}$ \\
\hline & $\begin{array}{l}\text { Lack of interprofessional communication can } \\
\text { lead to patient concern. }\end{array}$ & $\begin{array}{l}\text { "I was afraid that one was going to drop the ball on something and not pass something on, or you know." } \\
\text { (patient 11) }\end{array}$ \\
\hline & & $\begin{array}{l}\text { "I had numerous doctors who all seemed to not communicate with each other at all or did so by email or what- } \\
\text { ever. They didn't just sit down together and say we feel this way and we feel that way. I didn't like that at } \\
\text { all." (patient 10) }\end{array}$ \\
\hline \multirow[t]{3}{*}{$\begin{array}{l}\text { New opportunities due } \\
\text { to transition }\end{array}$} & $\begin{array}{l}\text { Patients see new doctor as opportunity for medi- } \\
\text { cal reevaluation. }\end{array}$ & $\begin{array}{l}\text { "I see it as two heads are better than one, three heads are better than one, four heads are better than one. } \\
\text { When people put their heads together to work towards a common goal, especially when they're, you } \\
\text { know, people working their craft, it can't be bad." (patient 9) }\end{array}$ \\
\hline & & $\begin{array}{l}\text { "I finally got my ears looked at... because l've asked to have my ears looked at since Monday... and the new } \\
\text { doc is trying to make an effort to look at them." (patient 39) }\end{array}$ \\
\hline & $\begin{array}{l}\text { Patients see service changeover as an } \\
\text { opportunity to form a better personal } \\
\text { relationship. }\end{array}$ & "Having a new hospitalist it gives you opportunity for a new beginning." (patient 11) \\
\hline \multirow[t]{3}{*}{ Bedside manner } & $\begin{array}{l}\text { Good bedside manner can assist in a service } \\
\text { changeover. }\end{array}$ & $\begin{array}{l}\text { "Some of them are all business-like but some of them are, 'Well how do you feel today? Hi, how are you?' So } \\
\text { this made a little difference. You feel more comfortable. You're going to be more comfortable with them. } \\
\text { Their bedside manner helps." (patient 16) }\end{array}$ \\
\hline & & $\begin{array}{l}\text { "It's just like when a doctor sits down and talks to you, they just seem more relaxed and more ... I know } \\
\text { they're very busy and they have lots of things to do and other patients to see, but while they're in there } \\
\text { with you, you know, you don't get too much time with them. So bedside manner is just so important." } \\
\text { (patient 24) }\end{array}$ \\
\hline & $\begin{array}{l}\text { Poor bedside manner can be detrimental in } \\
\text { transition. }\end{array}$ & $\begin{array}{l}\text { "B]ecause they be so busy they claim they don't have time just to sit and talk to a patient, and make sure } \\
\text { they all right." (patient 17) }\end{array}$ \\
\hline
\end{tabular}




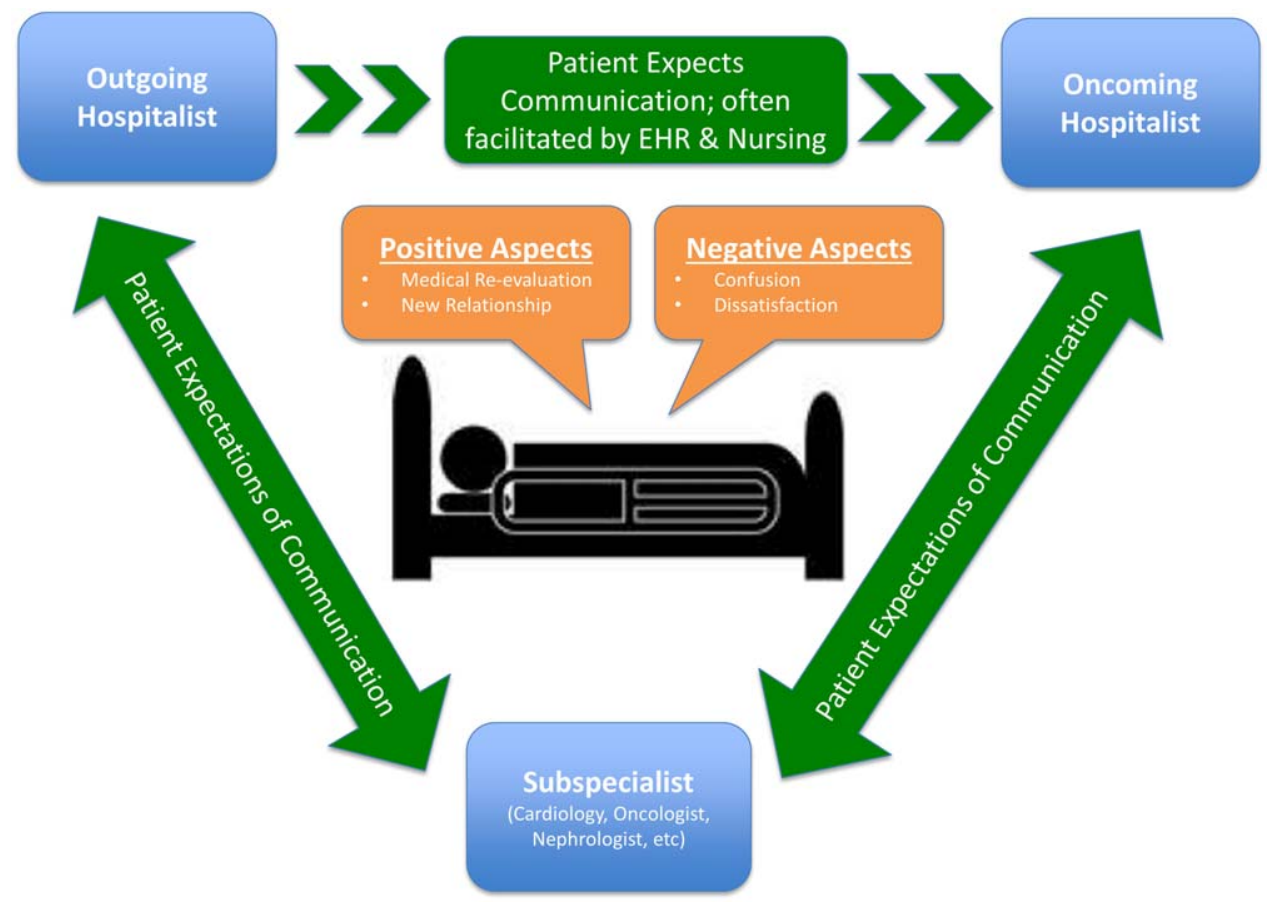

FIG. 1. Conceptual model of the ideal patient experience with a service handoff. Abbreviations: EHR, electronic health record.

Of the 6 themes, communication was found to be the most pertinent to our respondents. Because much of patient care is an inherently communicative activity, it is not surprising that patients, as well as patient safety experts, have focused on communication as an area in need of improvement in transition processes. ${ }^{17,18}$ Moreover, multiple medical societies have directly called for improvements within this area, and have specifically recommended clear and direct communication of treatment plans between the patient and physician, timely exchange of information, and knowledge of who is primarily in charge of the patients care. ${ }^{11}$ Not surprisingly, each of these recommendations appears to be echoed by our participants. This theme is especially important given that good physician-patient communication has been noted to be a major goal in achieving patientcentered care, and has been positively correlated to medication adherence, patient satisfaction, and physical health outcomes. ${ }^{19-23}$

Although not a substitute for face-to-face interactions, other communication interventions between physicians and patients should be considered. For example, "get to know me" posters placed in patient rooms have been shown to encourage communication between patients and physicians. ${ }^{24}$ Additionally, physician face cards have been used to improve patients' abilities to identify and clarify physicians' roles in patient care. ${ }^{25}$ As a patient put it, "If they got a new one [hospitalist], just as if I got a new medication...print out information on them...like where they went to med school, and stuff"(patient 13). These modalities may represent highly implementable, cost-effective adjuncts to current handoff methods that may improve lines of communication between physicians and patients.

In addition to the importance placed on physicianpatient communication, interprofessional communication between hospitalists and subspecialists was also highly regarded. Studies have shown that practice-based interprofessional communication, such as daily interdisciplinary rounds and the use of external facilitators, can improve healthcare processes and outcomes. ${ }^{26}$ However, these interventions must be weighed with the many conflicting factors that both hospitalists and subspecialists face on daily basis, including high patient volumes, time limitations, patient availability, and scheduling conflicts. ${ }^{27}$ None the less, the strong emphasis patients placed on this line of communication highlights this domain as an area in which hospitalist and subspecialist can work together for systematic improvement.

Patients also recognized the complexity of the transfer process between hospitalists and called for improved transparency. For example, patients repeatedly requested to be informed prior to any changes in their hospitalists, a request that remains consistent with current guidelines. ${ }^{11}$ There also existed a strong desire for a more formalized process of transitioning between hospitalists, which often described a handoff procedure that would occur at the patient's bedside. This desire seems to be mirrored in the data that show that patients prefer to interact with their care team at the bedside and report higher satisfaction when they are involved with their care. $^{28,29}$ Unfortunately, this desire for more direct interaction with physicians runs counter to the current 
paradigm of patient care, where most activities on rounds do not take place at the bedside. ${ }^{30}$

In contrast to patient's calls for improved transparency, an equally large portion of patients expressed relative indifference to the transition. Whereas on the surface this may seem salutary, some studies suggest that a lack of patient activation and engagement may have adverse effects toward patients' overall care. ${ }^{31}$ Furthermore, others have shown evidence of better healthcare experiences, improved health outcomes, and lower costs in patients who are more active in their care. ${ }^{30,31}$ Altogether, this suggests that despite some patients' indifference, physicians should continue to engage patients in their hospital care. ${ }^{32}$

Although prevailing sentiments among patient safety advocates are that patient handoffs are inherently dangerous and place patients at increased risk of adverse events, patients did not always share this concern. A frequently occurring theme was that the transition is an opportunity for medical reevaluation or the establishment of a new, possibly improved therapeutic alliance. Recognizing this viewpoint offers oncoming hospitalists the opportunity to focus on issues that the patient may have felt were not being properly addressed with their prior physician.

Finally, although our conceptual model is not a strict guideline, we believe that any future studies should consider this framework when constructing interventions to improve service-level handoffs. Several interventions already exist. For instance, educational interventions, such as patient-centered interviewing, have been shown to improve patient satisfaction, compliance with medications, lead to fewer lawsuits, and improve health outcomes. ${ }^{33-35}$ Additional methods of keeping the patient more informed include physician face sheets and performance of the handoff at the patient's bedside. Although well known in nursing literature, the idea of physicians performing handoffs at the patient's bedside is a particularly patient-centric process. ${ }^{36}$ This type of intervention may have the ability to transform the handoff from the current state of a "2-way street," in which information is passed between 2 hospitalists, to a "3-way stop," in which both hospitalists and the patient are able to communicate at this critical junction of care.

Although our study does offer new insight into the effects of discontinuous care, its exploratory nature does have limitations. First, being performed at a single academic center limits our ability to generalize our findings. Second, perspectives of those who did not wish to participate, patients' family members or caregivers, and those who were not queried, could highly differ from those we interviewed. Additionally, we did not collect data on patients' diagnoses or reason for admission, thus limiting our ability to assess if certain diagnosis or subpopulations predispose patients to experiencing a service handoff. Third, although our study was restricted to English-speaking patients only, we must consider that non-English speakers would likely suffer from even greater communication barriers than those who took part in our study. Finally, our interviews and data analysis were conducted by hospitalists, which could have subconsciously influenced the interview process, and the interpretation of patient responses. However, we tried to mitigate these issues by having the same individual interview all participants, by using an interview guide to ensure cross-cohort consistency, by using open-ended questions, and by attempting to give patients every opportunity to express themselves.

\section{CONCLUSIONS}

From a patients' perspective, inpatient service handoffs are often opaque experiences that are highlighted by poor communication between physicians and patients. Although deficits in communication and transparency acted as barriers to a patient-centered handoff, physicians should recognize that service handoffs may also represent opportunities for improvement, and should focus on these domains when they start on a new service.

Disclosures: All funding for this project was provided by the Section of Hospital Medicine at The University of Chicago Medical Center. The data from this article were presented at the Society of Hospital Medicine Annual Conference, National Harbor, March 31, 2015, and at the Society of General Internal Medicine National Meeting in Toronto, Canada, April 23, 2015. The authors report that no conflicts of interest, financial or otherwise, exist.

\section{References}

1. Sharma G, Fletcher KE, Zhang D, Kuo Y-F, Freeman JL, Goodwin JS. Continuity of outpatient and inpatient care by primary care physicians for hospitalized older adults. JAMA. 2009;301(16):1671-1680.

2. Nyweide DJ, Anthony DL, Bynum JPW, et al. Continuity of care and the risk of preventable hospitalization in older adults. JAMA Intern Med. 2013;173(20):1879-1885.

3. Agency for Healthcare Research and Quality. HCUPnet: a tool for identifying, tracking, and analyzing national hospital statistics. Available at: http://hcupnet.ahrq.gov/HCUPnet.jsp?Id=82B37DA366A36BAD\&Form= DispTab\&JS=Y\&Action=Accept. Accessed April 9, 2015.

4. Fletcher KE, Sharma G, Zhang D, Kuo Y-F, Goodwin JS. Trends in inpatient continuity of care for a cohort of Medicare patients 1996-2006. J Hosp Med. 2011;6(8):438-444.

5. Arora VM, Manjarrez E, Dressler DD, Basaviah P, Halasyamani L, Kripalani S. Hospitalist handoffs: a systematic review and task force recommendations. J Hosp Med. 2009;4(7):433-440.

6. Epstein K, Juarez E, Epstein A, Loya K, Singer A. The impact of fragmentation of hospitalist care on length of stay. J Hosp Med. 2010;5(6): 335-338.

7. Turner J, Hansen L, Hinami K, et al. The impact of hospitalist discontinuity on hospital cost, readmissions, and patient satisfaction. J Gen Intern Med. 2014;29(7):1004-1008.

8. O'Leary KJ, Turner J, Christensen N, et al. The effect of hospitalist discontinuity on adverse events. J Hosp Med. 2015;10(3):147-151.

9. Agency for Healthcare Research and Quality. HCAHPS Fact Sheet. CAHPS Hospital Survey August 2013. Available at: http://www.hcahpsonline.org/files/August_2013_HCAHPS_Fact_Sheet3.pdf. Accessed February 2, 2015.

10. Behara R, Wears RL, Perry SJ, et al. A conceptual framework for studying the safety of transitions in emergency care. In: Henriksen K, Battles JB, Marks ES, eds. Advances in Patient Safety: From Research to Implementation. Rockville, MD: Agency for Healthcare Research and Quality; 2005:309-321. Concepts and Methodology; vol 2. Available at: http://www.ncbi.nlm.nih.gov/books/NBK20522. Accessed January 15,2015

11. Snow V, Beck D, Budnitz T, et al. Transitions of care consensus policy statement American College of Physicians-Society of General Internal Medicine-Society of Hospital Medicine-American Geriatrics SocietyAmerican College of Emergency Physicians-Society of Academic Emergency Medicine. J Gen Intern Med. 2009;24(8):971-976.

12. Watling CJ, Lingard L. Grounded theory in medical education research: AMEE guide no. 70. Med Teach. 2012;34(10):850-861.

13. Boeije H. A purposeful approach to the constant comparative method in the analysis of qualitative interviews. Qual Quant. 2002;36(4): 391-409. 
14. Morse JM. The significance of saturation. Qual Health Res. 1995; 5(2):147-149.

15. O'Brien BC, Harris IB, Beckman TJ, Reed DA, Cook DA. Standards for reporting qualitative research: a synthesis of recommendations. Acad Med. 2014;89(9):1245-1251.

16. Tong A, Sainsbury P, Craig J. Consolidated criteria for reporting qualitative research (COREQ): a 32-item checklist for interviews and focus groups. Int J Qual Health Care. 2007;19(6):349-357.

17. Kripalani S, Jackson AT, Schnipper JL, Coleman EA. Promoting effective transitions of care at hospital discharge: a review of key issues for hospitalists. J Hosp Med. 2007;2(5):314-323.

18. The Joint Commission. Hot Topics in Healthcare, Issue 2. Transitions of care: the need for collaboration across entire care continuum. Available at: http://www.jointcommission.org/assets/1/6/TOC_Hot_ Topics.pdf. Accessed April 9, 2015.

19. Zolnierek KBH, Dimatteo MR. Physician communication and patient adherence to treatment: a meta-analysis. Med Care. 2009;47(8): $826-834$

20. Desai NR, Choudhry NK. Impediments to adherence to post myocardial infarction medications. Curr Cardiol Rep. 2013;15(1):322.

21. Zandbelt LC, Smets EMA, Oort FJ, Godfried MH, de Haes HCJM. Medical specialists' patient-centered communication and patientreported outcomes. Med Care. 2007;45(4):330-339.

22. Clever SL, Jin L, Levinson W, Meltzer DO. Does doctor-patient communication affect patient satisfaction with hospital care? Results of an analysis with a novel instrumental variable. Health Serv Res. 2008; 43(5 pt 1):1505-1519.

23. Michie S, Miles J, Weinman J. Patient-centredness in chronic illness: what is it and does it matter? Patient Educ Couns. 2003;51(3): 197-206.

24. Billings JA, Keeley A, Bauman J, et al. Merging cultures: palliative care specialists in the medical intensive care unit. Crit Care Med. 2006;34(11 suppl):S388-S393.
25. Arora VM, Schaninger C, D'Arcy M, et al. Improving inpatients' identification of their doctors: use of FACE cards. Jt Comm J Qual Patient Saf. 2009;35(12):613-619.

26. Zwarenstein M, Goldman J, Reeves S. Interprofessional collaboration: effects of practice-based interventions on professional practice and healthcare outcomes. Cochrane Database Syst Rev. 2009;(3):CD000072.

27. Gonzalo JD, Heist BS, Duffy BL, et al. Identifying and overcoming the barriers to bedside rounds: a multicenter qualitative study. Acad Med. 2014;89(2):326-334.

28. Lehmann LS, Brancati FL, Chen MC, Roter D, Dobs AS. The effect of bedside case presentations on patients' perceptions of their medical care. N Engl J Med. 1997;336(16):1150-1155.

29. Gonzalo JD, Wolpaw DR, Lehman E, Chuang CH. Patient-centered interprofessional collaborative care: factors associated with bedside interprofessional rounds. J Gen Intern Med. 2014;29(7):1040-1047.

30. Stickrath C, Noble M, Prochazka A, et al. Attending rounds in the current era: what is and is not happening. JAMA Intern Med. 2013; 173(12):1084-1089.

31. Hibbard JH, Greene J. What the evidence shows about patient activation: better health outcomes and care experiences; fewer data on costs. Health Aff (Millwood). 2013;32(2):207-214.

32. Greene J, Hibbard JH, Sacks R, Overton V, Parrotta CD. When patient activation levels change, health outcomes and costs change, too. Health Aff Proj Hope. 2015;34(3):431-437.

33. Smith RC, Marshall-Dorsey AA, Osborn GG, et al. Evidence-based guidelines for teaching patient-centered interviewing. Patient Educ Couns. 2000;39(1):27-36.

34. Hall JA, Roter DL, Katz NR. Meta-analysis of correlates of provider behavior in medical encounters. Med Care. 1988;26(7):657-675.

35. Huycke LI, Huycke MM. Characteristics of potential plaintiffs in malpractice litigation. Ann Intern Med. 1994;120(9):792-798.

36. Gregory S, Tan D, Tilrico M, Edwardson N, Gamm L. Bedside shift reports: what does the evidence say? J Nurs Adm. 2014;44(10):541-545. 